\title{
Development Control and Flood Risk: Analysis of Local Planning Authority and Developer Approaches to PPG25
}

\section{Introduction}

Development in flood plains is not a new phenomenon: in many cases the presence of a river has had a large part in the development of a town. Neither are concerns over flooding new: an Act of Parliament in 1531, affirming the powers of Sewer Commissioners, placed their role in the context of increasing incidents of flooding (Wynn, 2002). The Sewer Commissioners and their successors down to the current Environment Agency have had powers, but not duties, to maintain land drainage and flood defences. Specific powers to construct new flood defences were made available to the Sewer Commissioners during the nineteenth century. Since the Town and Country Planning Act 1947 powers have been available for local planning authorities to control development in flood plains. Howarth (2002, p.362) noted that the risks of flooding and the effects of development on flooding of neighbouring land have long been recognised as material considerations in the preparation of development plans and in development control. Howe and White (2004) pointed out that flood risk is only one of a number of sometimes conflicting considerations that have to be taken into account by local planning authorities. They placed the need for greater emphasis on the issue of flooding in the context of the social and economic effects of major flood events in 1998 and 2000 and the increasing likelihood of flooding arising from climate change. This is coupled with growing demand for housing placing pressure on flood plains: the House of Commons Select Committee on Environment, Transport and Regional Affairs (2000) reported that 4,000 houses were proposed on flood plains in 1996 compared with at least 20,000 in 2000.

This paper examines the relationships between developers, local authorities and housing developers concerning planning applications and flooding in England which is the part of the 
United Kingdom with greatest pressure for development. The research attempts to identify the perceptions and approaches of local planning authorities and applicants so that future guidance can be targeted to ensure the effective use of the development control process in achieving a sustainable approach to flood risk management.

It outlines previous government guidance to local planning authorities on flood risk matters and summarises the background to the introduction of Planning Policy Guidance PPG25 (Department for Transport, Local Government and the Regions, $2001^{\dagger}$ ). The provisions of PPG25 with respect to development control are outlined. Since much previous comment on the application of PPG25 has been based on anecdotal accounts, the present study has included surveys examining the practice and experience of local planning authorities and developers. The results of these surveys are presented and discussed. Support for the PPG25 approach from both local planning authorities and developers is found. From an analysis of the responses it is concluded that the recent introduction by the Environment Agency of National Standing Advice to the local planning authorities will overcome several of the problems in the operation of PPG25 to date. It will however require local planning authorities to consider how best to advise the many individuals making one off applications that are low risk in terms of development type and location.

\section{Circular 30/92}

Formal Government guidance on development and flood risk has long been issued. Although described as 'guidance' Howarth (2002) pointed out that this must be followed unless

\footnotetext{
${ }^{\dagger}$ Government departments having oversight over the planning process have undergone changes over time. In the period covered by this paper, the relevant departments have been as follows:

Department of the Environment (DOE)

Department of the Environment, Transport and the Regions (DETR)

Department for Transport, Local Government and the Regions (DTLR)

Office of the Deputy Prime Minister (ODPM)
} 
overridden by other material considerations. The version issued as Circular 30/92 (Department of the Environment, 1992) pointed out that the powers available to the then National Rivers Authority and other drainage bodies were limited to the control of activities immediately adjacent to water courses. It indicated that the Government expected local planning authorities to use their powers to guide development away from areas that may be affected by flooding, and to restrict development that would increase flood risk.

The circular stated that where flood defence considerations arose, they should always be taken into account by local planning authorities in preparing development plans and in determining planning applications. This was linked with an expectation that the National Rivers Authority would influence development patterns in a positive rather than a reactive way. An example was given of making available to local planning authorities results of surveys carried out as part of its flood defence functions under section 105(2) of the Water Resources Act 1991. The Circular stated that it wished these surveys to be the main input of the National Rivers Authority [as far as flooding issues were concerned] to the development plan process. It stated that the surveys should indicate where flood defence problems were likely and help to identify the extent of flood plains, washlands and other land liable to flood, in relation to risk.

The Circular cautioned that the surveys were indicative only and that local planning authorities would need to consult the National Rivers Authority before granting permission for individual developments. It was recommended that each local planning authority should seek to agree with the National Rivers Authority on areas and types of development about which consultations should take place. It was recognised however that the 14 day period sought by government for an initial National Rivers Authority response was short and that 
developers should be encouraged to undertake prior consultation with the National Rivers Authority where possible.

The Circular noted that it was the responsibility of the developer to show how any unacceptable flood risk identified by the National Rivers Authority arising from the proposed development would be mitigated or alleviated.

\section{Discussions on Change}

The "Bye report" (Bye and Horner, 1998) examined the circumstances surrounding major flooding that occurred over Easter 1998. It was commissioned by the Environment Agency, which had taken over the flood defence responsibilities of the National Rivers Authority in 1996. The terms of reference included examination of the flood events themselves, the operation of flood warning and emergency response procedures and interfaces between the Environment Agency and other bodies. Of particular relevance to the present study was the requirement to address the effectiveness and appropriateness of the current standards applying to flood defences including the effectiveness of the planning liaison process with regard to development in the flood plain. In this respect the report recognised the limitations of the Section 105(2) surveys and recommended consideration of an alternative approach in which flood plains are defined indicatively in a manner that acknowledges the uncertainties surrounding rainfall events and the response of watercourses to them. The report suggested that the main features of the alternative would involve:

- the Environment Agency advising local planning authorities of flood potential on the basis of maps showing known flood risk areas, defended and undefended, established from 
recorded events, and (distinguished from) possible flood risk areas, established by approximate modelling of topography, soil characteristics or arbitrary methods;

- developers being required to take full responsibility for confirming flood risk at proposed sites as well as the implications for vulnerable upstream and downstream areas.

The report did not give a definition of what was meant by 'arbitrary methods' nor how developers could 'confirm' flood risk. It could be inferred that it had in mind methods based on subjective judgement where modelling was not possible or realistic and that investigations into the effects of development on flood risk should be funded by developers.

The need for the production and delivery of flood warning hazard maps was also emphasised by the House of Commons Select Committee on Agriculture in its 1998 report on the organisation of flood and coastal defence, including the relationship with the planning process. The report stated that this must be the Environment Agency's highest priority.

The Bye Report noted that, although the Environment Agency is a statutory consultee in the planning process, its role on flooding matters is advisory and added, perhaps controversially, that in theory local planning authorities can disregard its advice. It considered that, in view of commitments given by local authorities to treat flood plain protection as an aspect of sustainable development, this is unlikely and suggested that recent planning liaison arrangements appeared to have worked effectively in support of the Environment Agency's flood plain policy. The Environment Agency did not support this statement in its evidence to the House of Commons Select Committee on Agriculture, saying there were "numerous examples” of instances where local planning authorities had effectively disregarded its advice (House of Commons Select Committee on Agriculture, 1998). The Bye Report did however note that there was evidence such advice provided by the National Rivers Authority's 
predecessors, the Regional Water Authorities, had been ignored and cautioned the Environment Agency to be prepared to defend its advice vigorously.

The Select Committee suggested that there was likely to be growing pressure on local planning authorities to permit development of flood plain land for residential purposes. It also noted evidence from Ernst and Young that local authorities generally stood to gain more from permitting flood plain development than prohibiting it. Various mechanisms for strengthening the Environment Agency’s powers were suggested including the Royal Town Planning Institute's statement that 'where there is a risk of flooding planning permission should be refused' by making flooding a material consideration for preventing planning approval. The Select Committee, on the basis of evidence and statements from the Environment Agency, stated that a clear presumption should be made against future development in flood plain land where the flooding risk attached to a particular development is deemed to outweigh the benefits. It also stated that 'in those exceptional circumstances where planning permission on land liable to flooding is considered, the Environment Agency should have powers to require developers to set aside monies for the provision of flood defence works both at the point of development, and upstream and downstream of it before planning permission is granted'.

In respect of the relationship between flooding and planning, the Government responded to the Bye and Select Committee reports by producing a consultation draft Planning Policy Guidance Note (Draft PPG25) (DETR, 2000) to replace Circular 30/92 . It sought to place responsibility on the developer to:

- determine whether any proposed development will be affected by flooding and whether it will increase flood risk elsewhere; and 
- $\quad$ satisfy the local planning authority that any flood risk can be successfully managed with the minimum environmental effect to ensure the safe development and secure occupancy of any site.

Its proposals would require all development plans to take account of flood risk issues at the relevant scale taking account of the information provided by the Environment Agency, inter alia via Section 105 maps. It indicated that the Environment Agency would contribute to the formulation of flood defence policies. It specifically identified susceptibility to flooding as a material planning consideration and proposed a risk based approach to proposals for development in flood risk areas. Where other material considerations outweighed the risk of flooding, Draft PPG25 expected the developer to fund any necessary flood protection works possibly through an agreement made under Section 106 of the Town and Country Planning Act 1990. Such agreements are legally enforceable against the developer. Local planning authorities would be expected to consult the Environment Agency, and, presumably in recognition of the extent of the work involved, the time period for the Environment Agency response was extended to 21 days. Draft PPG25 stated that local planning authorities should inform the Environment Agency if they considered other material considerations outweighed the Environment Agency’s objections.

In commenting on the draft the House Builders Federation, a trade body representing developers of all sizes, expressed concerns over four main issues (House Builders Federation, 2000):

- that the guidance was not sufficiently clear in advising that 'safe' development continued to be permissible;

- that the precautionary principle may lead to a presumption against development in areas of flood risk; 
- that the Environment Agency rather than developers is best placed to consider flooding issues; and

- the risk based approach should be consistent with the principle of permissible 'safe' development [i.e. development in accordance with Circular 30/92].

The House Builders Federation argued that the provisions of Circular 30/92 were adequate and that provided these were met there was no need for any presumption against, or veto on, development in floodplains. The Federation stated that a move away from the Circular 30/92 would have a significant effect on the ability of housebuilders to deliver sustainable development patterns necessary to meet social, economic and environmental objectives. It also expressed concern over the indicative nature of the floodplain maps to be produced by the Environment Agency and serious concern over the inclusion of the Environment Agency's flood risk model.

The House of Commons Select Committee on Environment, Transport and Regional Affairs (2000) stated that it had decided to undertake a brief enquiry into development affecting flood plains, not least so that the draft PPG25 received Parliamentary scrutiny. It agreed with House Builders Federation concerns in relation to infill development and brownfield sites. However, after noting that local authorities were broadly satisfied with the draft and that the Environment Agency considered that the guidance sought a firmer approach, it welcomed the Minister's statement that he planned to issue stronger guidance. The Committee, recognising that local authorities and developers lack relevant expertise, called for more weight to be given to Environment Agency advice than had been general in the past. The House of Commons Agriculture Select Committee (2001) again argued that there should be a clear presumption against development in flood plains where the Environment Agency deemed the flood risk to outweigh the advantages of the development proceeding. 


\section{PPG25}

The issued PPG25 (DTLR, 2001) has taken a viewpoint that largely reflects the submissions of the Environment Agency and the Select Committees and to a lesser extent the concerns of the House Builders Federation. It includes an expectation that local planning authorities will apply a sequential test in drawing up or revising development plans, with priority given to allocation sites for development in areas with little or no risk of flooding. Until development plans reflect this approach, the Government expects the sequential test to be applied to individual applications. Zones are based on Environment Agency data with no allowance made for the presence of flood defences.

Zone 3 covers the areas of high risk. In high risk undeveloped and sparsely developed areas new development is not considered suitable unless a particular location is essential. Where development is exceptionally permitted, it should be provided with the appropriate minimum standard of defence and should not impede flood flows or result in a net loss of flood plain storage. Already developed high risk areas may be suitable for development provided the appropriate minimum standard of protection of flood protection can be maintained for the lifetime of the development. Development in high risk areas should not be permitted if properly maintained existing defences would not provide an acceptable standard of safety over the lifetime of the development. Within functional flood plains built development should be exceptional and limited to essential transport and utilities infrastructure. Zone 3 areas, along with Zone 2 (low to medium risk areas) would not be considered suitable for essential civil infrastructure such as hospitals. 
In Zone 2 and Zone 3 areas appropriate flood risk assessment should be carried out at the time of the local plan (now local development framework) preparation or with the planning application. Zone 1 areas at little or no flood risk, defined as those with an annual probability of flooding of less than $0.1 \%$, should have no flood related planning constraints.

In applying the sequential test, local planning authorities are expected to consult the Environment Agency. Recognition is given to the conflict that might arise from the need to avoid social and economic stagnation or blight in areas where lower risk zones are not available.

Applicants are expected to discuss with the local planning authority the requirements they will be expected to satisfy and to consult the Environment Agency on the potential risks to the development, the likely effects of their proposals and the nature and effectiveness of mitigation measures. Appropriate flood risk assessment should be submitted with the application. Guidance on the content of such assessment is contained in an Appendix. PPG25 warns that failure to submit an appropriate assessment may lead to delay or refusal of permission. It is expected that normally any necessary flood defence work or mitigation will be funded by the developer. As was envisaged in the draft PPG25, this may involve the use of Section 106 agreements.

Local planning authorities are expected to consult with the Environment Agency and other bodies. The time scale of 21 days for response suggested in the draft is retained, along with the recommendation of pre-application consultations. Where a local planning authority considers that other material planning considerations outweigh the objections of the Environment Agency or other consultees on flooding issues, it is expected to inform the body of their intention to grant permission and give opportunity for further representations. 
The House Builders Federation (2001) provided an advice note on PPG25 for its members. As well as explaining the PPG25 regime, it commented that it considers the published guidance to be an improvement on the draft. It welcomed the expectation that the Environment Agency would:

- respond to consultation within 21 days;

- justify its objections as reasonable in all the circumstances; and

- $\quad$ produce well-founded objections that will stand scrutiny on appeal.

A large part of the House Builders Federation advice note was devoted to an explanation of the Environment Agency flood risk maps that were made available on the internet from December 2000. It pointed out that the maps showed only lateral extent and not depth of flooding and did not indicate the effects of flood defences.

The advice note finished with a comment that monitoring of the Environment Agency and local planning authorities’ implementation of PPG25 will be necessary, inter alia, to establish whether there are regional or local differences in its application.

\section{National Standing Advice}

National Standing Advice (Environment Agency, 2004) has now been issued to enable local planning authorities in England to make some decisions where flood risk is an issue without directly consulting the Environment Agency. A response matrix accompanies the advice. Use of the matrix overcomes some of criticisms of the PPG25 regime by for example removing the need to consult the Environment Agency in the case of applications for 
domestic and small scale industrial and commercial extensions in low to medium flood risk areas. The Environment Agency provides related guidance on minimum requirements for flood risk assessment depending on type of development and location. Apart from developments falling within the lowest risk of development type / location category, the standing advice is to refuse planning permission in the absence of a flood risk assessment. Specific guidance to the construction industry on flood risk assessment has now been published (CIRIA, 2004).

\section{High Level Target 12}

Following recommendations made by the House of Commons Select Committee on Agriculture (1998) the Government introduced a set of High Level Targets for flood and coastal operating authorities, including the Environment Agency. Target 12 requires the Environment Agency, in partnership with local planning authorities to report annually on:

- those local planning authority development plans upon which the Agency have commented, identifying plans which do, and do not, have flood risk statements in place; and

- the Agency’s response to planning applications, identifying cases where

(i) the Agency sustained objections on flood risk grounds; and

(ii) final decisions, either by the local planning authority or on appeal, were in line with, or contrary to, Agency advice.

Four such reports have now been produced (Environment Agency, 2001, 2002; Environment Agency and Local Government Association, 2003, 2004). The reports note that the number of adopted development plans without a flood risk statement is in decline. The number of 
planning applications on which the Environment Agency was consulted and required consideration on flood risk grounds has averaged about 22,600. The 2003 report, covering a period after the introduction of PPG25, comments that, in spite of a general increase in the number of applications received by local planning authorities, there had been a decline of $15 \%$ in the number on which the Environment Agency had been consulted on flood risk grounds. It stated that internal Environment Agency research had suggested that in some areas of England the Environment Agency was being consulted on less than $60 \%$ of applications in the flood plain. The Environment Agency stated that they believed there was a need for them to be made a statutory consultee on applications where there is a risk of flood. The subsequent year's report, whilst reporting a slight increase in the number of consultations, clarified the research as indicating the Environment Agency was only being consulted on 53\% of all "major" applications. The Agency state that they use the Office of the Deputy Prime Minister's definition of major residential development being 10 or more dwellings or a site area equal to or greater than 0.5 ha. For non residential development major is considered to be a floor space equal to or greater than $1000 \mathrm{~m}^{2}$ or a site area equal to or greater than 1 ha.

The number of consultations resulting in a sustained objection by the Environment Agency on flood risk grounds has more than doubled over the four years covered by the reports. A large proportion of the increase in objections related to the lack of flood risk assessments.

PPG25 expects local planning authorities to inform the Environment Agency when they conclude that other material considerations outweigh the Agency's objections. However the Environment Agency does not receive decision notices on all applications for which it sustained an objection. The percentage of cases in which such decisions have been notified to the Environment Agency has increased from 54\% to $78 \%$ in the past two reporting years. 
Where the Environment Agency received decision notices, about 37\% were contrary to its advice during the first two years of reporting and about $22 \%$ in the second two years. Lack of timely Environment Agency response is often given as the reason for decisions being made contrary to Environment Agency advice.

\section{Identification of Research Issues and Methodology}

A number of main issues arising from the High Level Target 12 reports stand out for further investigation:

1. the extent to which local planning authorities support the philosophy of PPG25 at the planning application stage;

2. applicant's awareness of, and approach to, flood risk issues, in particular their appreciation of the need for flood risk assessments; and

3. perceptions of the performance of the Environment Agency in dealing with consultation on planning applications.

A number of approaches were considered for gathering data for the research. It was not felt that it would be feasible to carry out sufficient structured interviews for the survey to be representative and therefore a questionnaire approach was used. Discussions were undertaken with a small number of local planning authority, Environment Agency and House Builders Federation staff to determine the issues considered to be relevant and to ascertain the ease with which proposed questions could be answered. Developed questionnaires were then prepared for anonymous completion by developers and local planning authorities. 
The responses are analysed to establish the extent to which they explain the issues identified in the High Level Target 12 reports and the implications of the implementation of the Environment Agency National Standing Guidance is discussed.

\section{The Surveys}

\section{The Survey Groups}

Questionnaires were sent to all planning authorities in England except County Councils and National Park Authorities. 98 completed questionnaires, representing a 27.6\% response rate, were returned.

130 questionnaires were sent to housing developers advertising residential property for sale in England and Wales. 48 responses were received representing a response rate of $37 \%$. Developers were asked to identify whether they were an independent entity or, if a subsidiary, whether their responses represented the whole group or just the subsidiary. $15 \%$ of responses were from independent entities, 38\% represented subsidiaries of groups and $47 \%$ represented groups as a whole. As the House Builders Federation provide guidance to members on flood risk management, it was felt pertinent to establish whether or not the organisations were members. $75 \%$ were members. The organisations were asked in which regions of England they operated and the approximate number of properties constructed. The replies indicated that they were responsible for the construction of some 19,200 properties annually. Figure 1 shows the distribution of this activity. Comparison with Office of National Statistics data on private sector housing indicates that the respondents were responsible for some $15 \%$ of current private sector housing development. It is apparent that the survey responses overrepresent those responsible for development in the south-east compared with other regions. 
This however is not considered as an issue as this region in particular is prone to pressure to develop on sites in floodplains.

Perception and Awareness of Flooding as an Issue

The local planning authorities were asked to indicate the importance of flooding as an issue to them. Only $11 \%$ of authorities stated that it was of no importance. Responses to questions on the current status and content of development plans confirmed the Environment Agency and Local Government Association (2004) observation that recent plans have made specific reference to flood issues, with a number now also including policies on sustainable drainage systems.

84\% of developers who responded said that they were aware of PPG25. Those not answering the question or giving an answer in the negative were cumulatively responsible for the construction of less than 400 properties annually. This lends support to the pattern of opinion of the local planning authorities that, unlike individual applicants, most developers had at least some knowledge of flooding issues, with national developers most likely to have good knowledge. The survey showed that membership of the House Builders Federation did not seem to be a factor in developer awareness. Local planning authority perceptions of developer awareness of flooding as an issue is summarised in Figure 2 and clearly shows property developers to be better informed than individual applicants or their professional representatives.

Provision of Further Guidance and Advice to Developers on Flooding 
To avoid abortive planning applications, developers need to pay attention to the content of development plans. Local Planning Authorities may supplement these with supplementary planning guidance that, though non-statutory, can make clear how policies in the development plans will be implemented. Only three authorities responding to the survey stated that they had issued such guidance on flooding issues, one authority said that flooding was covered in planning briefs and one said that they provided guidance on flooding on their web site. None of the four authorities that said they considered flooding to be an extremely important issue published guidance to developers.

Developers were asked to indicate how useful they found various sources of advice. The responses are summarised in Figure 3. There were no clear relationship between the pattern of responses and the size of developer. Developers were also asked whether, if it were possible to change the system, at which level they would prefer guidance on flooding issues to be issued. Whilst almost all of the developers stated a preference, this was not consistent: 19\% preferring advice at local level; 31\% advice at county level; 33\% at regional level and $15 \%$ at national level.

\section{Developer Approach to Planning and Flood Risk}

Awareness does not necessarily translate into compliance with the expectations of PPG25 with regard to flood risk assessment. Developers were asked to indicate whether presence on the flood risk map as a deterrent to seeking planning permission and how often they submitted flood risk assessments with their planning applications. The responses are summarised in Figure 4. This area was also explored with questions to the Local Planning Authorities with the responses summarised in Figure 2. This indicates that national developers are perceived by Local Planning Authorities to be most likely to initially submit a flood risk assessment 
with applications where flooding is an issue, even for that group the responses indicated that generally these are only received for about a quarter of the applications. There were some exceptions to this general pattern with some local planning authorities reporting that nearly all relevant applications from regional and national developers were accompanied by flood risk assessments.

A related issue is the approach taken by the Local Planning Authorities when the expected flood risk assessment was not submitted with the planning application. About three quarters of the local planning authorities said that they were prepared to accept without the submission of a flood risk assessment. About a fifth of the authorities said they would either advise the applicant to re-submit the application with the relevant assessment or would accept the application but advise the applicant to submit a flood risk assessment. Only one authority specifically said that they would decline to validate an application that lacked the required flood risk assessment. The developers were also asked for their experience in cases where they had not initially submitted a flood risk assessment. About $60 \%$ of the respondents indicated that under such circumstances the local planning authority would always or usually chase for this in circumstances where the development itself was at risk from flooding. This figure fell to $27 \%$ in cases where the developments were not themselves at risk but might increase the risk of flooding elsewhere.

\section{Relationship between Local Planning Authorities and the Environment Agency}

The local planning authorities were asked whether they always consulted the Environment Agency when an application involved flooding issues. $84 \%$ of respondents indicated that this was the case. Of those that did not do this, most operated an arrangement for selection based on a screening arrangement with the Environment Agency. Such arrangements took several 
forms such as the Agency making a selection from a list or by use of the Environment Agency’s Standing Advice Matrix. There was however a small number of authorities who would consult at the Planning Officer's discretion or only on applications for major developments.

PPG25 suggests a 21 day period for the Environment Agency to respond to consultations. The local planning authorities' experiences are summarised in Table 1. The table also shows that local planning authorities indicated that for both minor and major development they considered the Environment Agency's advice to be reasonable on about $90 \%$ of the applications and that even where they had some misgivings they usually followed it.

There is an expectation in PPG25 that, where the local planning authority is not intending to follow the advice of the Environment Agency, it should inform the Environment Agency who should have the opportunity to make further representations. Only $10 \%$ of local planning authority respondents indicated that they would not inform the Environment Agency of the planning outcome and 37\% in all cases. The remainder would inform the Agency under a variety of circumstances including $23 \%$ at the Agency's request, $12 \%$ where the Agency have made representation, 6\% where Agency's advice is not followed, and 10\% for major developments only.

About $90 \%$ of local planning authority respondents were aware of the existence of the Environment Agency Standing Advice and about 70\% of respondents to believe it useful to varying extents. As the survey took place shortly after the publication of the advice, it is likely that the distribution of responses may represent perceptions rather than experience. 
Developers were questioned on how often they considered imposed planning conditions or the requirement to enter a Section 106 agreement relating to flooding to be unreasonable. The responses are summarised in Table $1.31 \%$ of developers reported that such impositions had made a development unviable. Under such circumstances $60 \%$ of the affected developers had not proceeded with development as a result and $20 \%$ appealed against the planning decision.

Overall Views on Effectiveness of PPG25

77\% of local planning authority respondents felt the PPG25 regime to be effective. Reasons identified for non- or partial effectiveness included a sense that the approach was too broad and lacking in common sense, that the Environment Agency was expecting too much of local planning authorities, that the system was "over the top" for small developments, that the system was confusing for small developers, that there were conflicts with other government policies, and that there were poor links to PPG25 information on official websites.

Overall developer opinion on the effectiveness of PPG25 demonstrates a lower degree of support than shown by the local planning authorities with $60 \%$ feeling that the regime is effective. The most often cited reason for suggesting the regime was ineffective was the impression that standard responses were received rather individual consideration of particular sites. Other reasons included doubts on the ability of the Environment Agency to cope with the process, and conflicts between different Environment Agency and local planning authority offices. 


\section{Analysis}

\section{Introduction}

The survey confirms the view contained in recent High Level Target 12 reports that development plans now produced reflect the requirements of PPG25. The analysis that follows therefore concentrates on the development control stage. Whilst for convenience of presentation the material is dealt with under separate headings the issues are not necessarily independent of each other.

\section{Provision of Flooding Information to Developers}

All Circular 30/92 had to say about this was “Through the development plan and development control process developers need to be made aware of the risks in a specific area, the consequent constraints on development, and any ways in which these can be overcome” and "where local planning authorities are consulted by developers before a formal planning application is made ..... the local planning authority should advise the developer to consult the National Rivers Authority.” Whilst Section 105 surveys were made available to local planning authorities, there appears to have been no suggestion that they were made generally available to developers.

Expectations on information provision are a major difference between PPG25 and the Circular 30/92 regimes. PPG25 is set in the context of the general availability of the Environment Agency's indicative flood plain maps, available on the internet since the end of 2000. The initial versions of these maps were subject to criticism, misinterpretation and misrepresentation. The criticism could be justified: the maps only indicated the lateral extent 
of flood plains for annual probability of flooding from rivers of $1 \%$ and from the sea of $0.5 \%$ or, if greater, the highest known water level. This misinterpretation and misrepresentation however were not justified: the maps were accompanied with guidance (Environment Agency, 2000) clearly stating that the maps provided a general overview and that the floodplain areas shown did not take account of the existence of flood defences nor did they grade the level of risk within the flood plains shown. The guidance pointed out that further detail could be obtained from local Environment Agency offices. An explanation of annual probability and return periods was also provided.

PPG25 says that local planning authorities should ensure that applicants are informed of the fact that areas are within an area of flood risk preferably before a formal planning application is submitted and advise those making planning searches to contact the Environment Agency for detailed information on flood risk. It adds that there are obvious benefits in applicants consulting the Environment Agency before an application is submitted. Appendix D recognises that educating the public on flood risk and the measures they should take is one of the measures by which the Environment Agency exercises its duty of exercising a general supervision over all matters relating to flood defence.

Figure 3 summarising developer's evaluation of usefulness of information sources indicates that, whilst there is a wide range of responses, Environment Agency guidance is considered the most useful source. Unfortunately the wording of the question posed did not allow differentiation to be made between sources that were not useful because they were of poor quality and those that were not useful because of their relative unavailability. This may be particularly relevant to supplementary planning guidance that the survey shows to be issued comparatively rarely. On the face of it Figure 3 indicates a strong desire for information to be available at county or regional level. However when analysed in terms of the annual 
number of properties developed, the picture was different, reflecting a preference for regional or national guidance amongst the larger developers. The CIRIA (2004) guidance will clearly be useful to such developers.

Individual applicants are highlighted in Figure 2 as being particularly poorly informed on flooding matters. The developer survey was not able to investigate the needs of this group. However they are likely to be responsible for many of the minor developments submitted without flood risk assessments. The introduction of the Standing Advice Matrix will throw much of the process of assessing applications from this group directly onto the local planning authorities. The provision of guidance directly aimed at such small scale developers would do much to aid the development control function of the local planning authorities.

\section{Preparation of Flood Risk Assessments}

PPG25 identified that a flood risk assessment is an essential element in considering the viability of a development falling within Zones 2 and 3. Guidance within Appendix F recognises that the detail and technical content will vary depending on the nature and location of the development. It is of concern that the majority of local planning authorities stated they are prepared to accept applications for areas where flood risk is an issue without the submission of a flood risk assessment. Conflicting additional comments were received in some cases. One authority stated that it had refused to process applications without an assessment and that no challenge had yet been made to this approach. Others stated that they did not have the power to refuse to process such applications. The developers' responses confirm the willingness of many local planning authorities to process applications without a flood risk assessment, especially when the effects are likely to be off-site. The Target 12 reports show that lack of submission of flood risk assessments is a major reason for the Environment Agency objecting to applications with the latest (Environment Agency \& Local 
Government Association, 2004) reporting this as the reason in 51\% of sustained objections. There is a clear waste of resources involved in the approach currently adopted by many local planning authorities.

Many of the missing flood risk assessments relate to minor residential developments. These are likely to be submitted by individuals. Figure 2 shows the local planning authorities to consider this group to be particularly ignorant of flood risk issues. The local planning authorities may argue that this is the applicant's problem. However PPG25 does clearly state that local planning authorities should ensure that developers are made aware of the flood risk status of the land and it is tempting to suggest that it is unprofessional for an local planning authority to accept such applications in the knowledge of their likely rejection. It is considered that the introduction of the Standing Advice Matrix may considerably improve performance in this area as local planning authorities will themselves need to consider the adequacy of the Flood Risk Assessment.

It is of concern that, in spite of most of the developers responding to the survey indicating knowledge of PPG25, most do not submit flood risk assessments when it is appropriate to do so. The figures indicates a clear difference between their actions when the development itself may be vulnerable and when the development may lead to increased flood risk elsewhere. One is drawn to the conclusion that there is an attitude that "we will try to get away with it" amongst many developers. To some extent the attitude could reflect a continuation of the viewpoint expressed in House Builders Federation (2000) that it should be the Environment Agency rather than developers that makes assessments of flood risk. The CIRIA (2004) guidance may encourage developers to consider flood risk assessment as a routine part of the planning process. 
Environment Agency (2002) identified a steady rise in applications for development in indicative flood plains from 900 in 1996/97 to 4400 in 2001/02. These applications would have largely been initiated before the publication by the Environment Agency of indicative flood plain maps. Figure 4 summarises developers' responses on the effect of this information has on their attitudes towards development. It shows that there is a clear distinction depending on whether or not the land is already owned. There is a possibility that once current land banks are cleared there will be less pressure for development in such areas. It is however worth noting that the largest national developer responding to the survey, responsible for construction of some 4500 properties annually, indicated that the presence on the map would never be a deterrent regardless of whether or not the land was currently owned. This apparent defiance was tempered by the fact that the developer was also one that indicated it always submitted a flood risk assessment when their own development was at risk of flooding and would usually do so when the development increased the risk of flooding elsewhere.

It is felt that the mean and modal figures indicated in Table 2 best represent the opinion of the respondent developers on the reasonableness of planning conditions or the requirement to enter Section 106 agreements. Whilst it is to be noted that a third of developers, representing about half the annual property build in the survey, chose not to answer this question, it is apparent that developers as a whole are not opposed to reasonable measures required to mitigate flood risk. The 15 developers who reported that such requirements had made a development unviable all had an annual build of less than 500 properties. The $20 \%$ of affected developers who indicated that they appeal actually represents only 3 respondents each having an annual build of between 350 and 500 properties. It can be surmised from the 
forgoing that in general the imposition of measures to mitigate flood risk is acceptable to the industry.

\section{Consultation with Environment Agency}

Under Circular 30/92 it was expected that each local planning authority should seek agreement with the National Rivers Authority (subsequently the Environment Agency) on areas and types of development about which consultation would take place. Whilst some initial guidance was contained within the circular, it was inevitable that variations in practice would occur, especially since the Environment Agency inherited roles from a number of regional water authorities. In reporting on a period still covered by the Circular 30/92 regime, the Environment Agency (2001) stated that screening criteria have been agreed with the Planning Officers’ Society, a non statutory body which represents senior professionals and managers within local planning authorities. PPG 25 identifies applications likely to require particular consideration of, and consultation on, flood risk issues, broadly similar to those mentioned in Circular 30/92 but with the indicative flood plain maps substituted for the Section 105 plans. As indicated earlier in this paper the number of applications which the Environment Agency says it is being consulted under the PPG25 regime is low. The fact that $84 \%$ of the respondents to the current survey claimed to consult on all applications involving flood issues does not necessarily contradict the Environment Agency research since it is likely that local planning authorities which avoid consultation will tend not to respond to such surveys. The variety of reasons reported as selection criteria for those local planning authorities which do not consult on all applications could reflect the variety of practices that developed under the Circular 30/92 regime as well as the transition to use of the Standing Advice Matrix. 
Although Table 1 shows “on time” as the modal response for Environment Agency responses reported by the local planning authorities, it represents only a quarter to a third of replies. The lower median response for major development is of concern. Examination of the Target 12 reports shows the dominance of consultations for developments classified as "minor" by the Agency and it can be concluded that the number of these received may have overwhelmed the Environment Agency and left it under-resourced to deal adequately with the major developments. This is hardly surprising in view of the concern noted by Bye \& Horner (1998) over the loss of in-house expertise and reduction in flood defence staff over the period since functions were transferred to regional water authorities in 1974. The use of the Standing Advice Matrix is likely to act as a useful filter in ensuring that the Environment Agency is able to concentrate on those applications having the greatest potential impact. In view of the survey date of summer 2004, the number of local planning authorities making use of the Standing Advice Matrix, so soon after its introduction, is encouragingly high. This possibly reflects the effectiveness of the training in its use provided by the Environment Agency to local planning authority officers.

\section{Overall Effectiveness of the PPG25 Regime}

Both local planning authorities and developers generally consider the regime to be effective. There is a certain commonality amongst the dissenters, centred around concerns that the Environment Agency responses have tended not to take individual site circumstances into account. This cannot be divorced from the reduction in levels of staff having specialised knowledge in flood defence matters. The recent issue of Standing Guidance to local planning authorities may enable the Environment Agency to give fuller attention to the most significant applications. 


\section{Conclusions}

In spite of anecdotal comments to the contrary, most local planning authorities support the philosophy of PPG25 and feel it is effective. Developers and local planning authorities were generally willing to accept the representations of the Environment Agency. Where this was not the perception, a common reason cited was that the process did not pay sufficient attention to the circumstances of individual cases. This was coupled with an impression that the Environment Agency was under - resourced to cope with the demands made on it resulting in responses on occasion being received too late for local planning authorities to take them into account in planning decisions.

One major concern of the Environment Agency has been the large number of applications that have not been accompanied by flood risk assessments. The research has confirmed that although a large proportion of developers responding state that they have knowledge of PPG25, they nevertheless are reluctant to submit such assessments. This is particularly so when the development affects other locations than the site itself. Responses from the local planning authorities indicate that many are prepared to process applications without them. It appears that one reason for this is a fear that they do not have the power to do otherwise.

A further issue that has been of concern to the Environment Agency is that local planning authorities have not always consulted them on applications where flood risk is an issue and even when they have done so have not followed its advice. The survey has shown a wide range of policies on consultation used by the local planning authorities. It is likely that this may reflect the continuation of practices under the previous Circular 30/92 and earlier regimes. Where timely advice was received from the Agency it was generally incorporated 
in the planning decision even when the local planning authority had some misgivings over it. However the survey revealed that often the Agency's comments were received too late to be taken into account. The perception gained is that the process has overwhelmed the ability of the Agency to cope with a large number of minor applications and that responses are often standard in nature and do not reflect the circumstances of individual sites.

It is considered that the introduction by the Environment Agency of the Standing Guidance Matrix for local planning authorities will address many of the above concerns because:

- Environment Agency resources can be targeted at those applications having the greatest potential risk; and

- the local planning authorities will themselves face the need to make decisions on many minor applications. They are unlikely to want to do this without a flood risk assessment and will therefore start to insist on these being submitted with applications.

Whilst the CIRIA (2004) guidance on flood risk assessments is likely to aid the commercial developer, the need for appropriate guidance for the many individual applicants must be addressed.

\section{References}

Bye, P. and Horner, M. (1998) Easter 1998 Floods: Report of the Independent Review Team to the Board of the Environment Agency (Bristol, Environment Agency).

CIRIA (Construction Industry Research and Information Association) (2004) Development and Flood Risk - Guidance for the Construction Industry, Report C624 (London, CIRIA). 
Department of the Environment (1992) Circular 30/92: Development and Flood Risk (London, HMSO).

Department of the Environment, Transport and the Regions (2000) New Planning Policy

Guidance Note 25: Development and Flood Risk (London, DETR).

Department for Transport, Local Government and the Regions (2001) Planning Policy

Guidance Note 25: Development and Flood Risk (London, DTLR).

Environment Agency (2000) Indicative Floodplain Maps, http//146.1014.38/wiyby/html/iflood_about.htm [accessed $18^{\text {th }}$ December 2000].

Environment Agency (2001) High Level Target 12: Development in Areas at Risk of Flooding Report to DEFRA and DTLR for Year Ending 31 ${ }^{\text {st }}$ March 2001 (Bristol, Environment Agency).

Environment Agency (2002) High Level Target 12: Development in Areas at Risk of Flooding Report to DEFRA and ODPM for Year Ending $31^{\text {st }}$ March 2002 (Bristol, Environment Agency).

Environment Agency (2004) National Standing Advice to Local Planning Authorities for Planning Applications: Development and Flood Risk (Bristol, Environment Agency).

Environment Agency \& Local Government Association (Environment Agency and Local Government Association) (2003) High Level Target 12: Development in Areas at Risk of 
Flooding Joint Report to DEFRA and ODPM for Year Ending $31^{\text {st }}$ March 2003 (Bristol, Environment Agency).

Environment Agency \& Local Government Association (Environment Agency and Local Government Association) (2004) High Level Target 12: Development in Areas at Risk of Flooding Joint Report to DEFRA and ODPM for Year Ending $31^{\text {st }}$ March 2004 (Bristol, Environment Agency).

House Builders Federation (2000) Response to New Planning Policy Guidance Note25 Development and Flood Risk Consultation Draft (London: House Builders Federation ).

House Builders Federation (2001) HBF Advice Note: Planning Policy Guidance Note 25 Development and Flood Risk (London, House Builders Federation ).

House of Commons Select Committee on Environment, Transport and Regional Affairs (2000) Development on, or Affecting, the Flood Plain, Session $2000-20022^{\text {nd }}$ Report (London, House of Commons).

House of Commons Select Committee on Agriculture (1998) Flood Defence, Session 1997$19986^{\text {th }}$ Report (London, House of Commons).

House of Commons Select Committee on Agriculture (1998) Flood Defence: Follow-up, Session $2000-20013^{\text {rd }}$ Report (London, House of Commons).

Howarth, W. (2002) Flood Defence Law, (Crayford, Shaw and Sons). 
Howe, J. \& White, I. (2004) Like a fish out of water: the relationship between planning and flood risk management in the UK, Planning, Practice \& Research 19(4), pp. 415-425.

Wynn, P.G.L. (2002) Flood defence and the surveyor: what's new?, Structural Survey 20(4), pp. 117-122. 

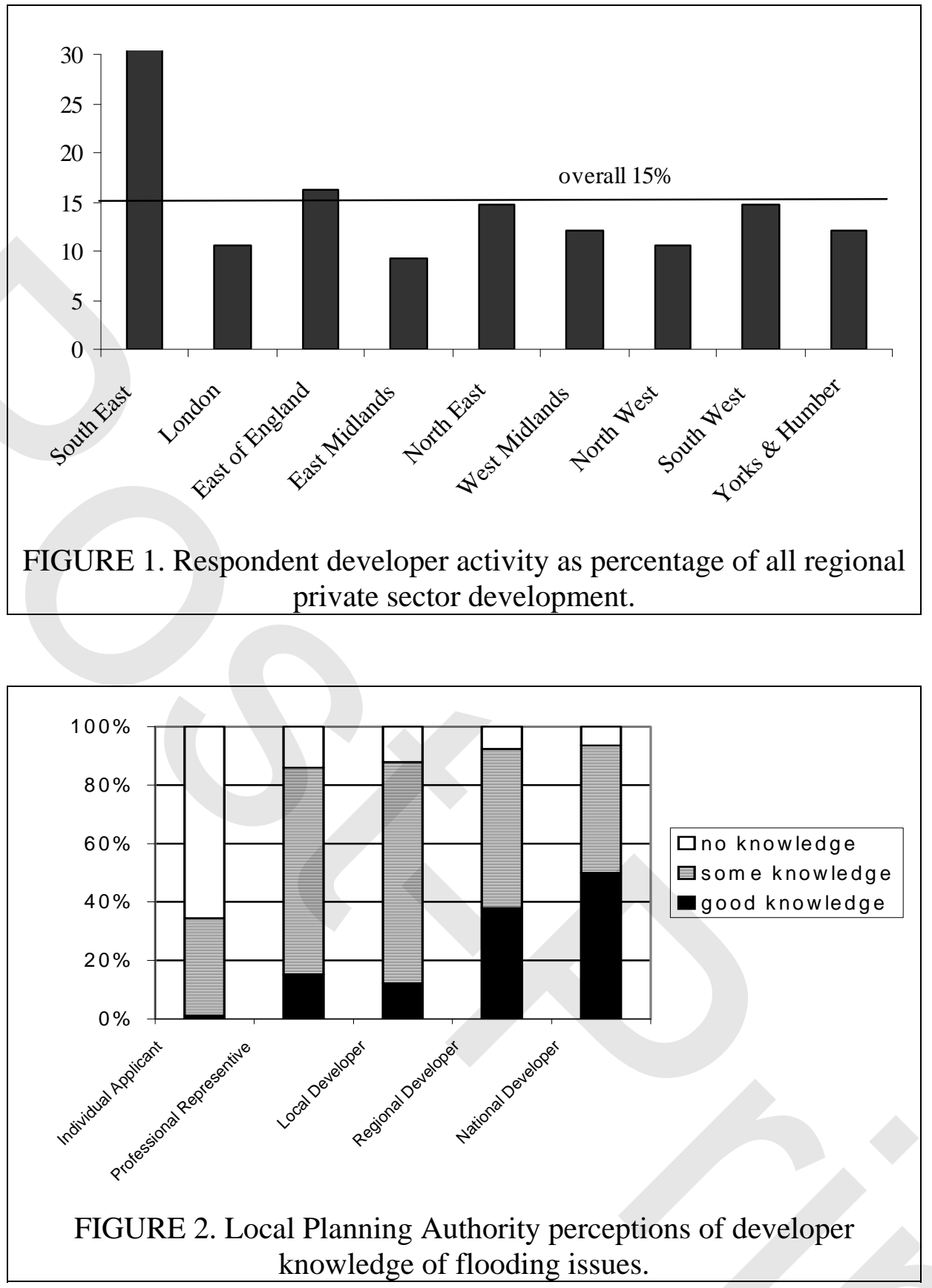


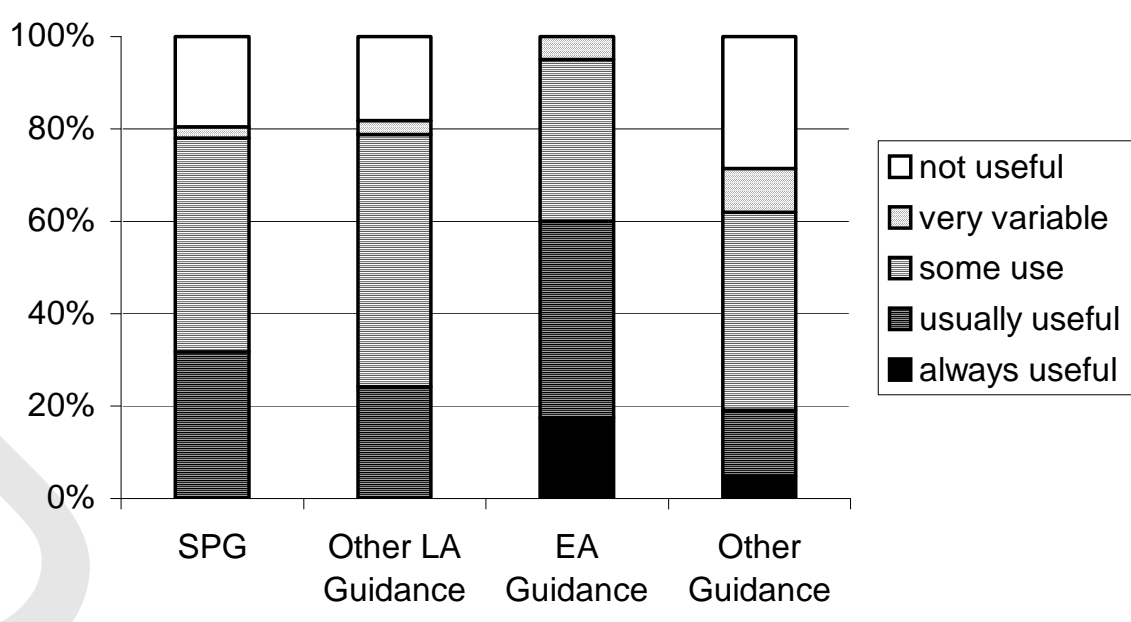

FIGURE 3. Respondent developers evaluation of usefulness of guidance

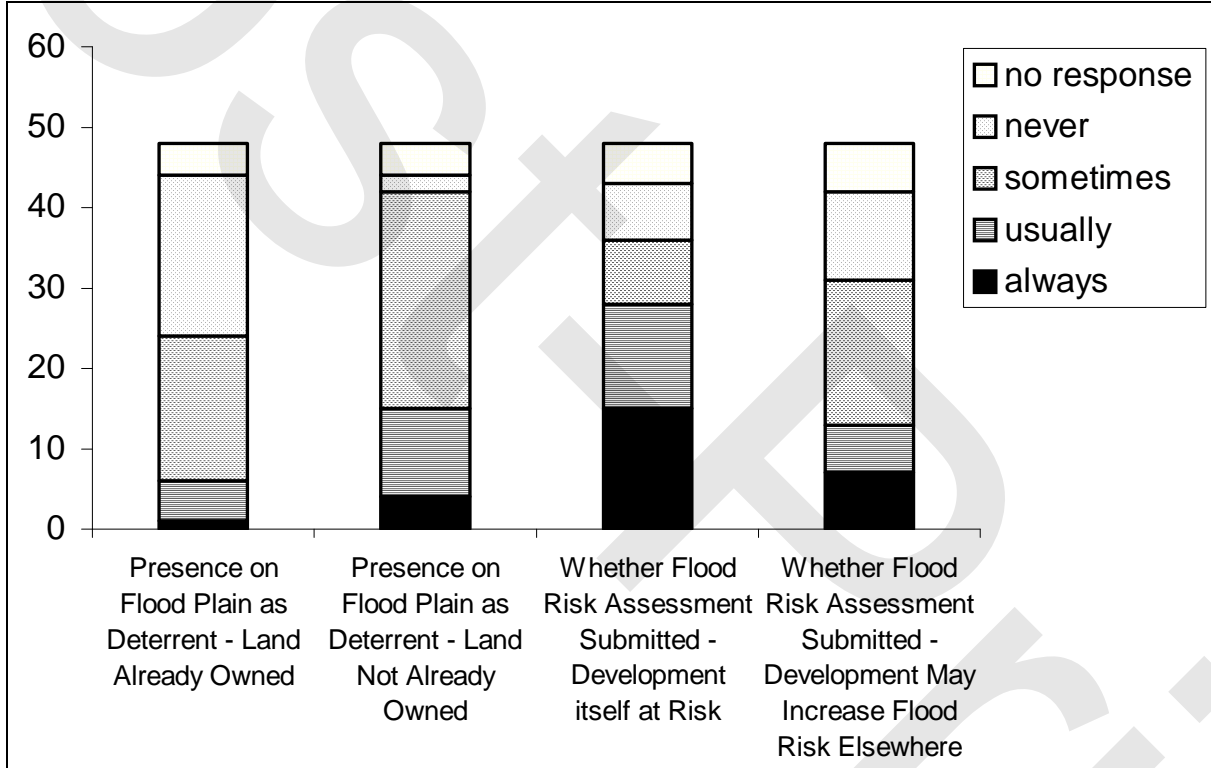

FIGURE 4 Developer responses to presence on flood plain as a deterrent and submission of flood risk assessments 
TABLE 1 Local Planning Authorities' estimates of Environment Agency response time and their responses to it

Received in time Considered reasonable

Incorporated

$\begin{array}{llll}\text { Minor } & \text { Major } & \text { Minor } & \text { Major }\end{array}$
development development development development development development

$\begin{array}{lcccccc}\text { Mean } & 78 & 74 & 88 & 91 & 96 & 97 \\ \text { Median } & 90 & 80 & 95 & 98 & 100 & 100 \\ \text { Mode } & 100 & 100 & 100 & 100 & 100 & 100 \\ \begin{array}{l}\text { Percentage of } \\ \text { modal } \\ \text { responses }\end{array} & 32 & 26 & 34 & 42 & 61 & 61 \\ & & & & & & \end{array}$

TABLE 2 Developers' perceptions of percentage of occasions conditions or requirement to enter Section 106 Agreement is unreasonable

Minor Major development development

Minimum

0 0

Maximum 100 100

Mean 32 28

Median 20 20

Mode 0 0

Number of 8

modal responses 